\title{
Variation of some planetary seismic hazard indices on the occasion of Lefkada, Greece, earthquake of 17 November, 2015
}

\author{
Dimitrios N. Arabelos*,1, Michael E. Contadakis ${ }^{1}$, George S. Vergos ${ }^{1}$, \\ Christos Skeberis ${ }^{2}$, Tomas D. Xenos ${ }^{2}$, Spiridon D. Spatalas ${ }^{1}$ \\ (1) Department of Geodesy and Surveying, Aristotle University of Thessaloniki, Thessaloniki, Greece \\ (2) Department of Electrical \& Computer Engineering, Aristotle University of Thessaloniki, Thessaloniki, Greece
}

Article history: received July 2, 2018; accepted July 3, 2019.

\begin{abstract}
In this paper we investigate the variation of the tidal triggering effect efficiency, by means of the tidal seismicity compliance parameter $\mathrm{p}$, and the lower Ionosphere variations, by means of the variation of the High-Frequency limit, $f_{o}$, of the ionospheric turbulence content with the time and space proximity to the site of the earthquake occurrence as well as by the intensity variations of VLF signals transmitted over the seismic area. It is shown that the "Earth tides-seismicity compliance parameter" $p$ may be used as a medium time earthquake warning while the frequency content of the ionospheric turbulence over the earthquake epicenter, deduced directly from GPS network TEC observations or indirectly through the VLF transmission network, may be used for the short time earthquake forecasting, deserving the special attention of the authorities, the scientists and the society.
\end{abstract}

Keywords: Tidal triggering, Seismicity, Ionospheric turbulence, Brownian Walk, Hilbert Huang Transform.

\section{Introduction}

By the term "Planetary seismic hazard indices" we mean parameters or observables which indicate the degree of the mutual interactions of tectonic active areas on the earth surface with some parts or phenomena of the Geosphere and the near Earth space. In this paper we investigate the variation of the tidal triggering effect efficiency, by means of the tidal seismicity compliance parameter $p$, [Arabelos et al., 2016; Contadakis et al., 2009; 2012a; Vergos et al., 2015], and the lower ionosphere variations, by means of the variation of the High-Frequency limit, $f_{0}$, of the ionospheric turbulence content [Contadakis et al., 2008; 2012b; 2015; Roznoi et al., 2012] with the time and space proximity to the site of the earthquake occurrence as well as by the intensity variations of VLF signals transited over the seismic area [Skeberis, et al., 2015]. In the following present the results of our investigation: (1) On the maps of the tidal seismicity compliance parameter $p$, over the Greece in order to find any indication of increasing tectonic stress criticality for the year 2015 of the area of Ionian islands in relation to other areas in Greece, which points to the area of a possible strong earthquake. (2) On the High- Frequency limit $f_{\mathrm{o}}$, of the ionospheric turbulence content, measured analyzing TEC variations, in order to find any increases as the site and the moment of the earthquake occurrence is approaching, pointing to the earthquake locus. (3) On the observational data from the receiver of INFREP network in Thessaloniki, Greece $\left(40.59^{\circ} \mathrm{N}, 22.78^{\circ} \mathrm{E}\right)$, which monitor VLF transmitters based in Tavolara, 


\section{Dimitrios N. Arabelos et al.}

Niscemi, Italy, Keflavik, Iceland, and Anthorn, UK, in order to see if the signals from the two VLF European transmitters, transmitted over Lefkada, indicate enhanced high frequency variations, in accordance to the result of the TEC analysis.

\section{The Lefkada 2015 earthquake event}

On November $17^{\text {th }}, 2015$ at 9:10 LMT an earthquake of Magnitude 6.0 occurred $9 \mathrm{~km} \mathrm{SSW}$ of Lefkada. A large number of aftershocks follow the main shock, 22 of them are of magnitude ranging between $\mathrm{M}=4$ and $\mathrm{M}=5.1$. Table 1 displays the main characteristic of the shocks with $M \geq 4$.4. The earthquake source is located on the North segment, the Lefkada segment, of the well known strike slip Cephalonian Transform Fault.

\begin{tabular}{ccccccc} 
No & DateGMT & Location & Latitude(o) & Longitude(o) & Depthkm & Magnitude \\
\hline 1 & $2015 / 11 / 21 ~ 00: 41: 56$ & $1.4 \mathrm{~km}$ WSW of Lefkada & 38.71 & 20.62 & 9 & 4.6 \\
\hline 2 & $2015 / 11 / 2023: 37: 04$ & $1.4 \mathrm{~km}$ WSW of Lefkada & 38.71 & 20.62 & 9 & 4.4 \\
\hline 3 & $2015 / 11 / 20$ 09:33:14 & $10.7 \mathrm{~km}$ SSW of Lefkada & 38.63 & 20.58 & 11 & 4.6 \\
\hline 4 & $2015 / 11 / 2005: 12: 24$ & $30.1 \mathrm{~km}$ SSW of Lefkada & 38.47 & 20.49 & 12 & 4.8 \\
\hline 5 & $2015 / 11 / 1813: 03: 14$ & $0.5 \mathrm{~km}$ NW of Lefkada & 38.72 & 20.63 & 8 & 4.6 \\
\hline 6 & $2015 / 11 / 1812: 15: 38$ & $14.2 \mathrm{~km}$ NNW of Lefkada & 38.84 & 20.59 & 17 & 4.9 \\
\hline 7 & $2015 / 11 / 1805: 18: 13$ & $26.0 \mathrm{~km}$ SSW of Lefkada & 38.50 & 20.52 & 14 & 4.5 \\
\hline 8 & $2015 / 11 / 1719: 39: 34$ & $3.4 \mathrm{~km}$ WSW of Lefkada & 38.70 & 20.60 & 8 & 4.5 \\
\hline 9 & $2015 / 11 / 1712: 37: 56$ & $2.4 \mathrm{~km} \mathrm{SE}$ of Lefkada & 38.70 & 20.65 & 5 & 4.5 \\
\hline 10 & $2015 / 11 / 1711: 57: 25$ & $2.7 \mathrm{~km}$ SW of Lefkada & 38.70 & 20.61 & 10 & 4.4 \\
\hline 11 & $2015 / 11 / 1708: 33: 40$ & $9.8 \mathrm{~km}$ SW of Lefkada & 38.65 & 20.56 & 9 & 5.1 \\
\hline 12 & $2015 / 11 / 1707: 10: 07$ & $5.9 \mathrm{~km} \mathrm{SSW} \mathrm{of} \mathrm{Lefkada}$ & 38.67 & 20.60 & 11 & 6.0 \\
\hline
\end{tabular}

Table 1. The strongest shocks of the 17th November event.

The area is tectonically very active and has been thoroughly studied by seismologist on the occasion of strong earthquake occurrence[Scordilis et al., 1985; Louvari et al., 1999; Papadopoulos et al., 2003; Valkaniotis et al., 2014]. Figure 1 displays the Cephalonian Transform Fault and the locus of the main shock.

\section{Earth tide seismicity compliance parameter $p$ maps}

Based on results of our investigation on earth tide triggering effect on earthquake generation [Contadakis et al., 2008; 2012a; Vergos et al., 2015], we consider the confidence level of earthquake occurrence - tidal period accordance, which we call "earth tide-seismicity compliance parameter $p$ ", as an index of tectonic stress criticality for earthquake occurrence and we construct maps of $p$ 's over all the area of Greece for each year from 2003 to 2015.

For the construction of the "earth tide seismicity compliance parameter" $p$ maps we use the NOA -Athens Catalogues. We collected 12424 earthquakes which occurred from 2013.01.01 to 2015.12.31 within the area bounded by $32.5^{\circ} \leq \varphi \leq 42.5^{\circ}, 18.5^{\circ} \leq \lambda \leq 28.5^{\circ}$. Table 2 displays these earthquakes. The whole area of Greece is divided in square subareas $\left(2^{\circ} \times 2^{\circ}\right)$ and the earth tide seismicity compliance parameter $p$ for each subarea was calculated. Since the purpose of the maps is to provide a comprehensive and quick overview of the risky areas, a smoothing procedure was applied. Thus for the construction of the maps, we used the following method: in the center of every $2^{\circ} \times 2^{\circ}$ cell we placed the edges of the four neighboring cells, so that each quarter of this cell is 


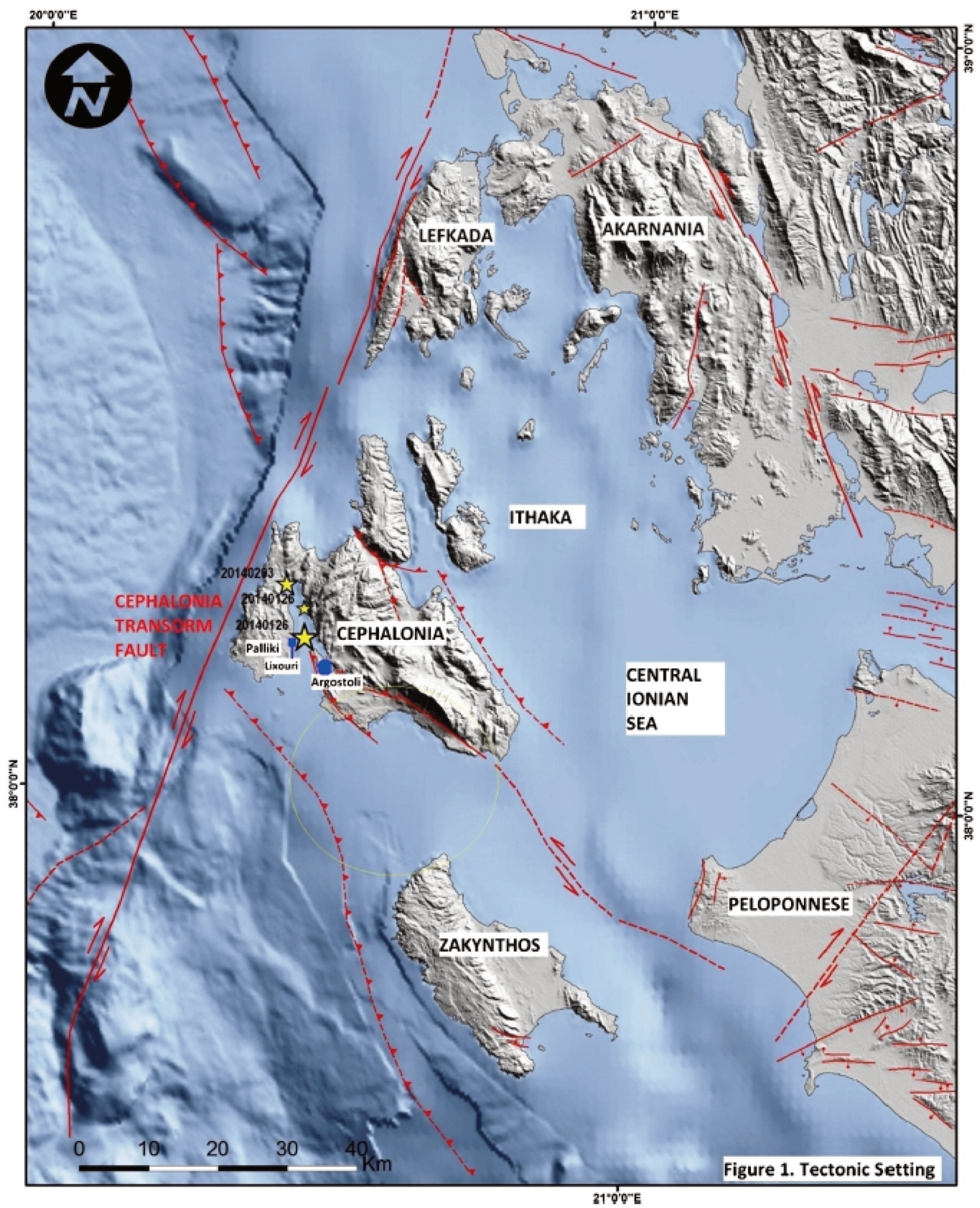

Figure 1. The Cephalonian Transform Fault (quoted from Valkaniotis et al. 2014). The white star indicates the site of the 17/11/2015 event in Lefkada. The yellow stars indicate the sites of the Jan 26-Feb 3, 2014 events of Cephalonia.

mixed with the corresponding quarters of the four neighboring cells. The result is the smooth transition from one color to the corresponding neighbor, without creating a mosaic difficult to read. For this procedure 88 cells were needed (because on the map the dimension longitude is less than the latitude). Furthermore, it has to take into account, that the number and the distribution of $p$ values is not the same within each cell. Finally, it is important to stress that this smoothing procedure has the disadvantage of lowering the position in the colored scale of the risky areas which are in immediate contiguity with calm areas. 


\begin{tabular}{cccc} 
Year & Events & Focal Depthkm & ML \\
\hline 2013 & 3737 & $2-178$ & $2.5-6.2$ \\
\hline 2014 & 4940 & $1-197$ & $2.5-6.3$ \\
\hline 2015 & 3737 & $0-220$ & $2.5-6.1$ \\
\hline
\end{tabular}

Table 2. The earthquakes occurred in the area of Greece in the years 2013-2015.

\subsection{Method of Analysis}

As we have done in similar studies [Contadakis et al., 2008; 2012a; Vergos et al., 2015], in order to check the possible correlation between Earth tides and earthquake occurrence we check the time of occurrence of each earthquake in relation to the sinusoidal variation of Earth tides and investigate the possible correlation of the time distribution of the earthquake events with Earth tides variation. Since the periods of the Earth tides component are very well known and quite accurately predictable in the local coordination system we assign a unique phase angle within the period of variation of a particular tidal component, for which the effect of earthquake triggering is under investigation, with the simple relation:

$$
\varphi_{i}=\left\{\left(\frac{\left(t_{i}-t_{0}\right)}{T d}\right)-\operatorname{int}\left(\frac{\left(t_{i}-t_{0}\right)}{T d}\right)\right\} \times 360^{\circ}
$$

where $\varphi_{i}=$ the phase angle of the time occurrence of the $i$ earthquake in degrees,

$t_{i}=$ the time of occurrence of the $i$ earthquake in Modified Julian Days (MJD),

$t_{o}=$ the epoch we have chosen in MJD,

$T_{d}=$ the period of the particular tidal component in Julian Days.

We choose as epoch $t_{0}$, i.e. as reference date, the time of the upper culmination in Thessaloniki of the new moon of January 7, 1989 which has MJD $=47533.8947453704$. Thus, the calculated phase angle for all the periods under study has 0 phase angle at the maximum of the corresponding tidal component (of course M2 and S2 has an upper culmination maximum every two cycles). As far as the monthly anomalistic moon concern the corresponding epoch $t_{0}$ is January 14,1989 which has MJD $=47541.28492$.

We separate the whole period in 12 bins of $30^{\circ}$ and stack every event according to its phase angle in the proper bin. Thus, we construct a Cumulative Histogram of earthquake events for the tidal period under study.

In order to check the compliance of the earthquake frequency distribution periods with the tidal periods we use the well known Shuster's test [Shuster, 1897; see also Tanaka et al., 2002; 2006 and Cadicheanu et al., 2007]. In Shuster's test, each earthquake is represented by a unit length vector in the direction of the assigned phase angle $\tilde{a}_{i}$. (where. $\left|\tilde{a}_{i .}\right|=\varphi_{\mathrm{i}}$ ). The vectorial sum $D$ is defined as:

$$
D^{2}=\left(\sum_{i=n}^{N} \cos \alpha_{i}\right)^{2}+\left(\sum_{i=n}^{N} \sin \alpha_{i}\right)^{2}
$$

where $N$ is the number of earthquakes. When $\alpha_{i}$ is distributed randomly, the probability to be the length of a vectorial sum equal or larger than $D$ is given by the equation:

$$
p=\exp \left(-\frac{D^{2}}{N}\right)
$$

Thus, $p<5 \%$ represents the significance level at which the null hypothesis that the earthquakes occurred randomly with respect to the tidal phase is rejected. This means that the smaller the $p$ is the greater the confidence level of the results of the Cumulative Histograms is, i.e the phase of the earthquake occurrence comply better with the tidal phase. Thus in the following we call $p$ "earth tide-seismicity compliance parameter $p$ ". It is obvious that the compliance parameter $p$ is an index of tectonic stress criticality for earthquake occurrence.

Finally, it should be noted that the total number of the shocks for each year is greater than 30 for all the years. This means that the normal distribution approach on which Shuster test is based is valid for all the years. 


\subsection{Results}

Figures 2, 3, and 4 display the earthquake seismicity Compliance parameter $p$ of the Lunar Monthly Synodic tidal period for the years 2013, 2014, 2015. It is realized that the earth tide-seismicity compliance parameter $p$ points to the broader area of significant earthquakes $(M \geq 4.5)$ with a very high consistency. In particular, while in the year 2013 the tectonic stress criticality index (earthquake seismicity Compliance parameter $p$ ) is insignificant for the area of Cefalonian Transform Fault, in the years 2014 and 2015 has reach the highest value (due to the smoothing effect the area appears be of middle value Compliance parameter. In fact the Compliance parameter is $\mathrm{p}=0$ at the cell of the earthquake i.e has the highest possible value).

In February of 2014 a double strong earthquake of Magnitudes 6.4 and 5.8 occurred on South segment (Cefalonian segment) of the Cefalonian Transform Fault, while on November, 17 of 2015 occurred a double strong earthquake of Magnitudes 6.0 and 5.4 on the Northern segment (Lefkada segment) of the Cefalonian Transform Fault.

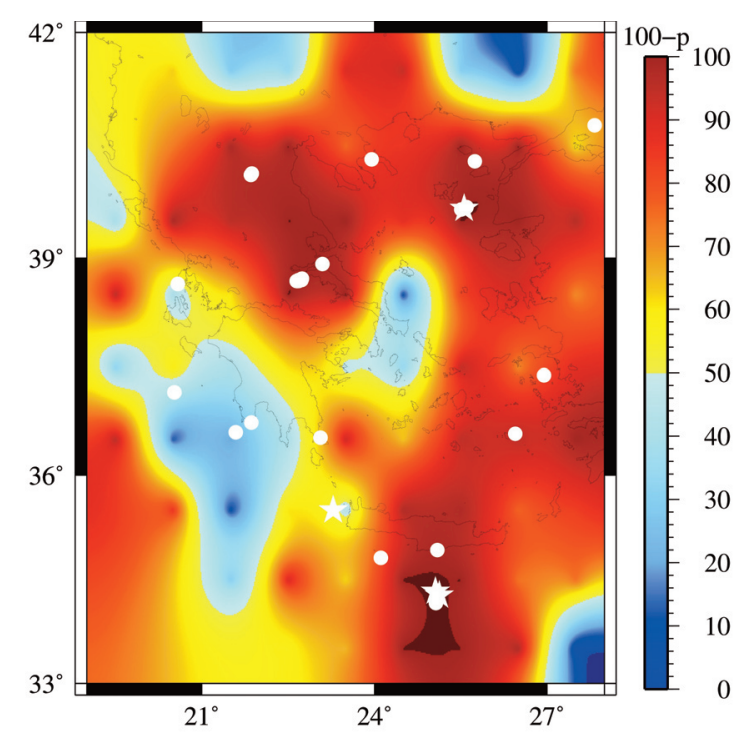

Figure 2. Compliance parameter $p$ of the Lunar Monthly Synodic tidal period for the year 2013. White marks indicate Earthquake epicenters: circles $4.5<\mathrm{M}<5.5$, stars $\mathrm{M} \geq 5.5$

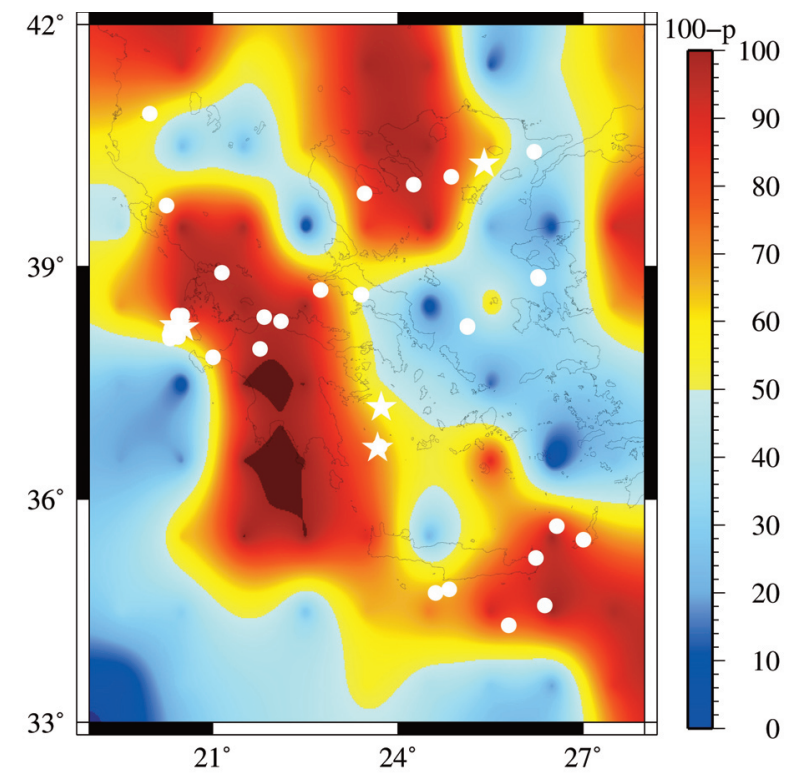

Figure 3. Compliance parameter $p$ of the Lunar Monthly Synodic tidal period for the year 2014. White marks indicate Earthquake epicenters: circles $4.5<\mathrm{M}<5.5$, stars $\mathrm{M} \geq 5.5$ 


\section{Dimitrios N. Arabelos et al.}

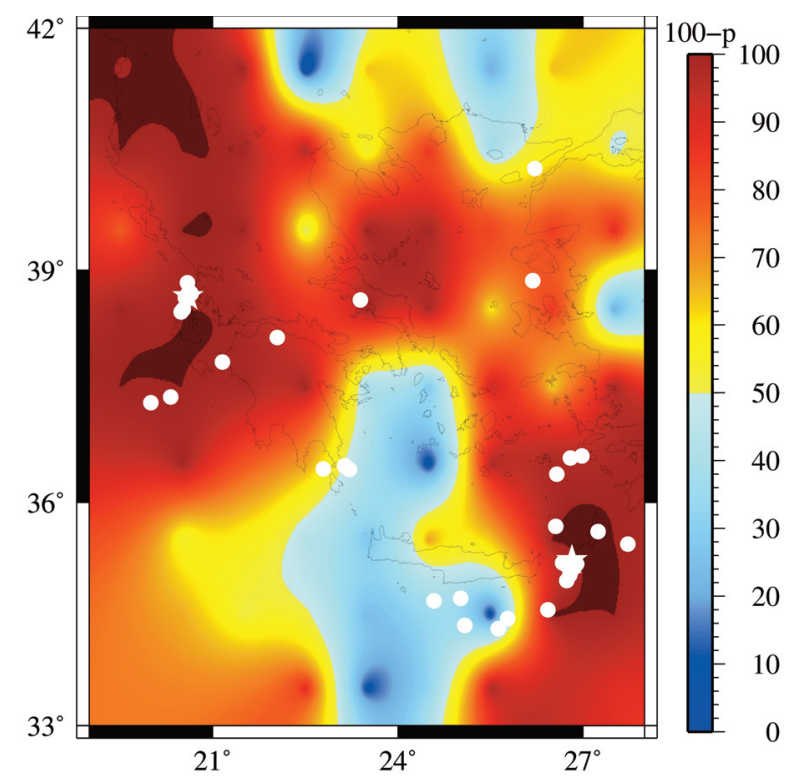

Figure 4. CoCompliance parameter $p$ of the Lunar Monthly Synodic tidal period for the year 2015. White marks indicate Earthquake epicenters: circles $4.5<\mathrm{M}<5.5$, stars $\mathrm{M} \geq 5.5$

From these maps we realize that from the 70 earthquakes with $M>4.5$ which happened in these three years, 62 occurred within the areas of high tectonic stress that is a $88.6 \%$ of success alarm. In addition all the 9 strong earthquakes $(M>5.5)$ occurred also within the areas of high tectonic stress that is a $100 \%$ of success alarm. It has to be stressed that critical tectonic stress do not in general forecast strong earthquake. The final result depends on the tectonic geology of the area.

Table 3 is a synopsis of the seismicity in Greece during the years 2013, 2014 and 2015. The upper part of the table includes the 11 earthquakes with $M \geq 5.5$ and the down the 116 , with $M \geq 4.5$. We consider as shallow events up to $40 \mathrm{~km}$ depth and as deep events with depth $>40 \mathrm{~km}$.

As it is shown in the table there is only one $p<5 \%$ representing the null hypothesis that the earthquakes occurred randomly with respect to the tidal phase, is rejected.

\begin{tabular}{ccccccc} 
& \multicolumn{7}{c}{ M $\geq 5.5$} \\
Year & 2013 & 2014 & 2015 & & & \\
\hline Depth & Sallow & Deep & Sallow & Deep & Sallow & Deep \\
\hline Number of EQ & 3 & 0 & 3 & 3 & 2 & 0 \\
\hline$p$ & 0.49 & - & 0.21 & 0.14 & 0.40 & - \\
\hline Year & 2013 & 2014 & 2015 & & & \\
\hline Depth & Sallow & Deep & Sallow & Deep & Sallow & Deep \\
\hline Number of EQ & 28 & 2 & 38 & 5 & 30 & 9 \\
\hline$p$ & 0.02 & 0.58 & 0.86 & 0.63 & 0.10 & 0.69 \\
\hline
\end{tabular}

Table 3. Compliance parameter $p$ of the Lunar Monthly Synodic tidal period for the years 2013, 2014, 2015. 


\section{TEC variation over mid latitude Europe}

In the following we investigate the variations of TEC over the broader area of Ionian Islands before and during the seismic activity of $17^{\text {th }}$ of November, 2015. To this purpose we use the TEC estimates provided by IONOLAB (http://www.ionolab.org) [Arikan et al., 2009] for 8 mid latitude GPS stations of EUREF which cover epicentre distances from the active area ranging from $371 \mathrm{~km}$ to $1862 \mathrm{~km}$ for the time period between 01/10/2015 and $30 / 11 / 2015$. The selected GPS stations have about the same latitude and are expected to be affected equally from the Equatorial Anomaly as well as from the auroral storms. Table 4 displays the 8 EUREF stations while Figure 6 displays the locus of the eight GPS stations and of the main shock. The IONOLAB TEC estimation system uses a single station receiver bias estimation algorithm, IONOLAB-BIAS, to obtain daily and monthly averages of receiver bias and is successfully applied to both quiet and disturbed days of the ionosphere for station position at any latitude. In addition, TEC estimations with high resolution are also possible [Arikan et al., 2008]. IONOLAB system provides comparison graphs of its TEC estimations with the estimations of the other TEC providers of IGS in its site. In this work only TEC estimations in perfect accordance among all providers were used. The TEC values are given in the form of a time series with a sampling gap (resolution) of 2.5 minutes.

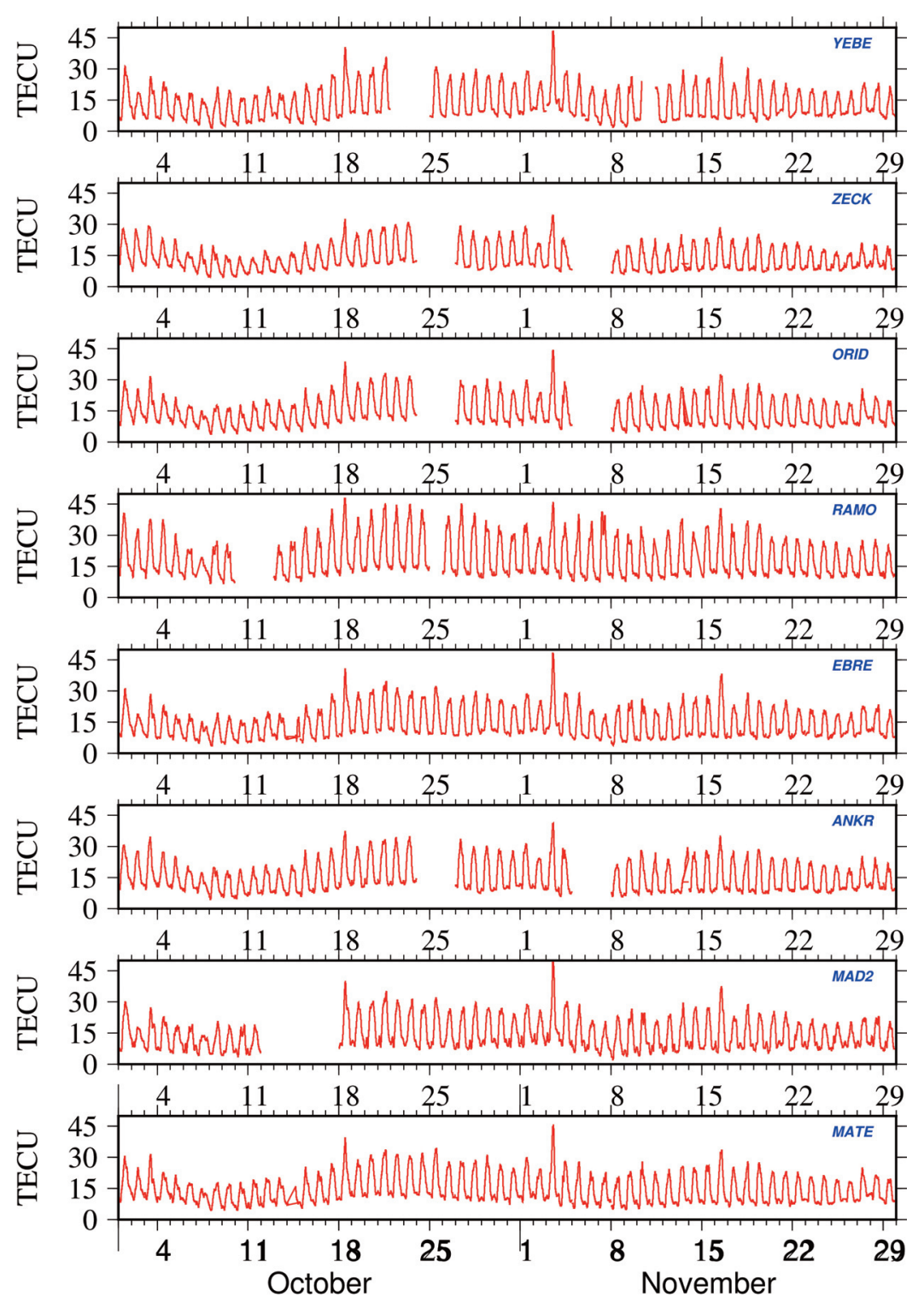

Figure 5. Variations of TEC over the 8 EUREF stations data during the time period of 01/10/2015 to 30/11/2015 
Dimitrios N. Arabelos et al.

\begin{tabular}{cccc} 
GPS station & Latitude $\left({ }^{\circ}\right.$ North) & Longitude $\left({ }^{\circ}\right.$ East) & Distance (km) \\
Yebes & 40.533615 & 03.111166 & 1561.0 \\
\hline Zelenchukskaya & 43.916985 & 41.577686 & 1861.7 \\
\hline Ohrid & 41.123657 & 20.801771 & 371.1 \\
\hline Mizpe-Ramon & 30.610846 & 34.802021 & 1504.6 \\
\hline Roquetes & 40.775860 & 00.431372 & 1788.5 \\
\hline Ankara & 39.936031 & 32.860733 & 1061.9 \\
\hline Robledo & 38.758064 & 02.450208 & 489.2 \\
\hline Matera & 40.666946 & 16.604445 & 4.5 \\
\hline
\end{tabular}

Table 4. Distance of GPS stations from the epicenter of the earthquake.

However, in time periods of uneven variations of TEC, the provider change the sampling gap (resolution) to 2.0 or 1.0 or even 0.5 minute in an unpredictable way, a fact which hardens the FFT elaboration of the time series. So, special attention was given in order to analyze segments of data with the same sampling gap. Figure 5 displays the variations of TEC over the 8 EUREF stations data during the time period of 01/10/ 2015 to $30 / 11 / 2015$.

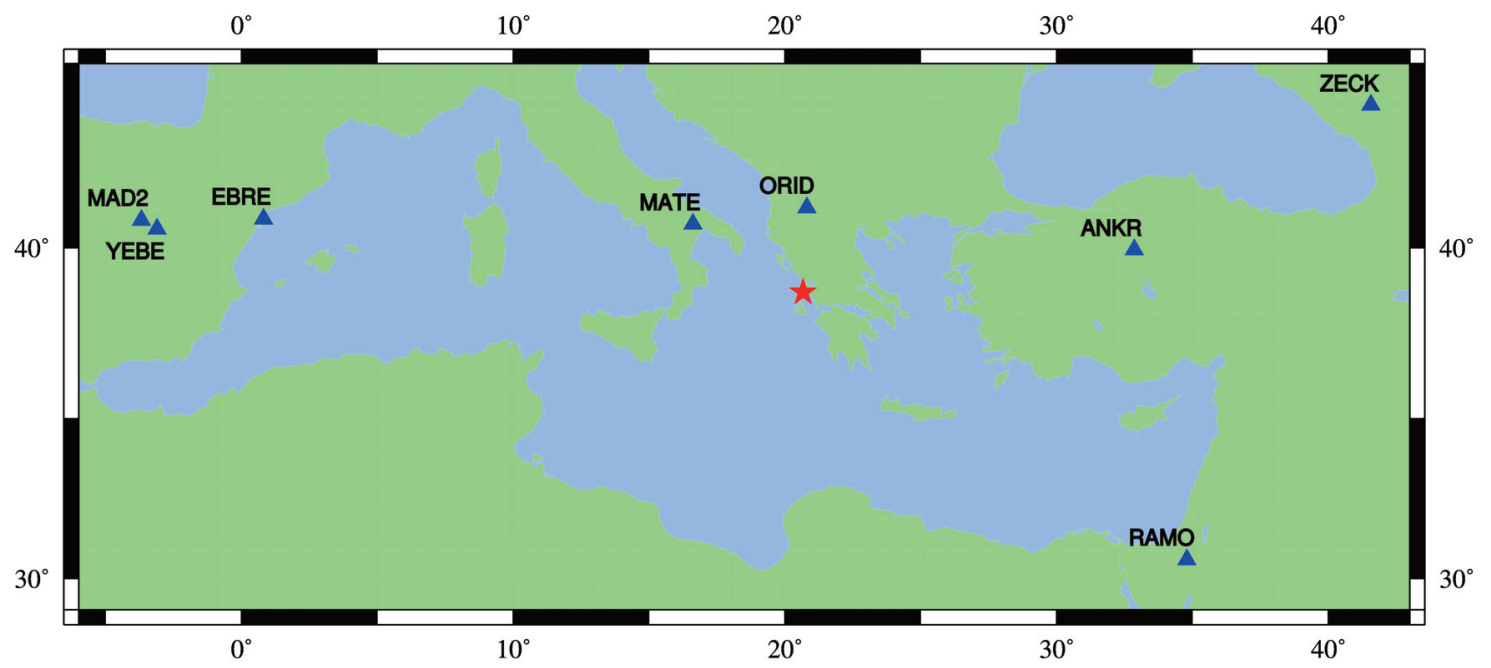

Figure 6. The stations of the network (in blue) and the earthquake of November 17, 2015 (in red).

\subsection{Geomagnetic and Solar activity indices}

The variations of the geomagnetic field were followed by the Dst index and the planetary Kp three hour indices quoted from the site of the Space Magnetism Faculty of Science, Kyoto University (http://swdcwww.kugi.kyotou.ac.jp/index.html) for the time period of our data. Figure 7 displays the Dst index variations on November of 2015. 

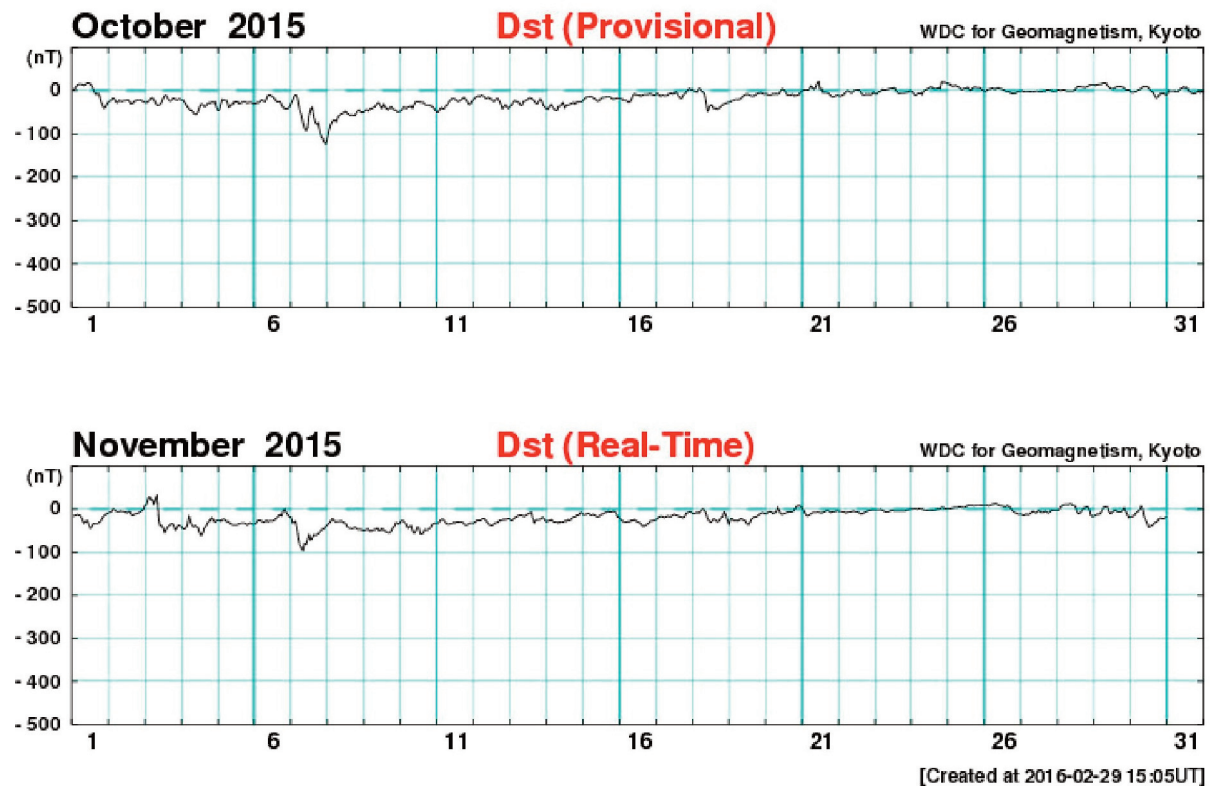

Figure 7. Dst-index variations on October and November of 2015.

\subsection{Fast Fourier Transform Analysis}

The Power Spectrum of TEC variations will provide information on the frequency content of them. Apart of the well known and well expressed tidal variations, for which the reliability of their identification can be easily inferred by statistical tests, small amplitude space-temporal transient variations cannot have any reliable identification by means of a statistical test. Nevertheless, looking at the logarithmic power spectrum we can recognize from the slop of the diagram whether the contributed variations to the spectrum are random or periodical. If they are random the slop will be 0 , which correspond to the white noise, or -2 which correspond to the Brownian walk, otherwise the slop will be different the so-called Fractal Brownian walk [Turcotte, 1997]. This means that we can trace the presence of periodical variations in the logarithmic power spectrum of TEC variations.

This method was successfully applied in our previous work [Contadakis et al., 2008; 2012b; 2015] in order to find the frequency content of TEC turbidity. It is realized that the upper frequency limit $f_{\mathrm{o}}$ of the spectrum of TEC variations increases as we approach the source of the ionospheric turbidity modulation, in our case the earthquake preparation activity.

The qualitative explanation of this phenomenology can be offered on the basis of the LAIC mechanism: Tectonic activity during the earthquake preparation period produces anomalies at the ground level which propagate upwards in the troposphere as Acoustic or Standing gravity waves [Hayakawa et al., 2011; Hayakawa 2011]. These Acoustic or Gravity waves affect the turbidity of the lower ionosphere, where sporadic Es-layers may appear too, and the turbidity of the F layer. Subsequently the produced disturbance starts to propagate in the ionosphere's waveguide as gravity wave and the inherent frequencies of the acoustic or gravity wave can be traced on TEC variations (i.e. the frequencies between $0.003 \mathrm{~Hz}$ (period $5 \mathrm{~min}$ ) and $0.0002 \mathrm{~Hz}$ (period $100 \mathrm{~min}$ ), which according to Molchanov et al. [2004; 2006] correspond to the frequencies of the turbulent induced by the LAIC coupling process to the ionosphere). As we move far from the disturbed point, in time or in space, the higher frequencies (shorter wavelength) variation are progressively attenuated.

\subsection{Results}

Figures 8 and 9 display the variation of TEC turbulence frequency limit $f_{\mathrm{o}}$ over the selected EUREF GPS stations. Both graphs indicate time and space convergence of increasing frequency limit $f_{\mathrm{o}}$ to the earthquake of 17 November occurrence. Hobara et al. [2005] in a study on the ionospheric turbulence at low latitudes concluded that the 


\section{Dimitrios N. Arabelos et al.}

attribution of the turbulence to earthquake process and not to other sources, i.e. solar activity, storms etc are not conclusive. Nevertheless in our case, the steady monotonic, time and space, convergence of the frequency limit $f_{\mathrm{o}}$ increment, to the occurrence of the Lefkada earthquake is a strong decisive indication that the observed turbidity is generated by the Lefkada earthquake preparation process.

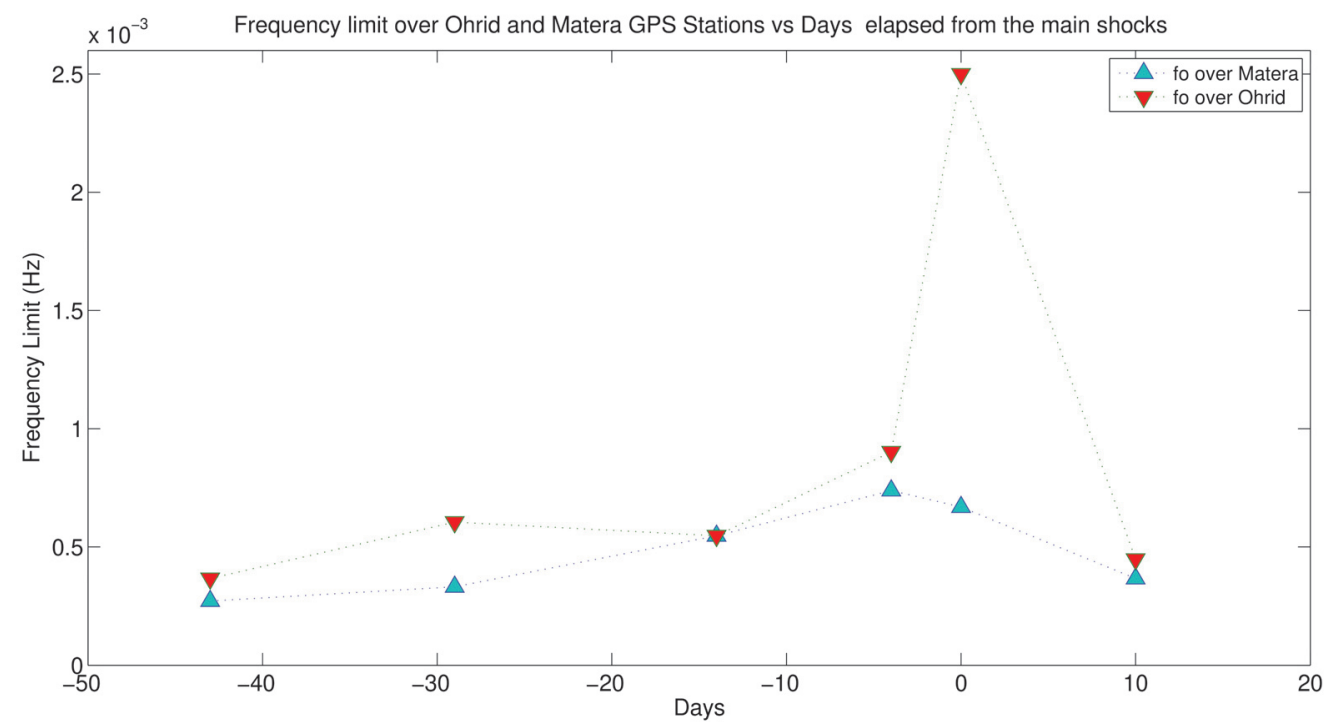

Figure 8. Variation of TEC turbulence frequency limit fo over the closest to Lefkada GPS Stations of Ohrid and Matera, with the time distance from the day of the earthquake of 17 November, 2015 occurrence.

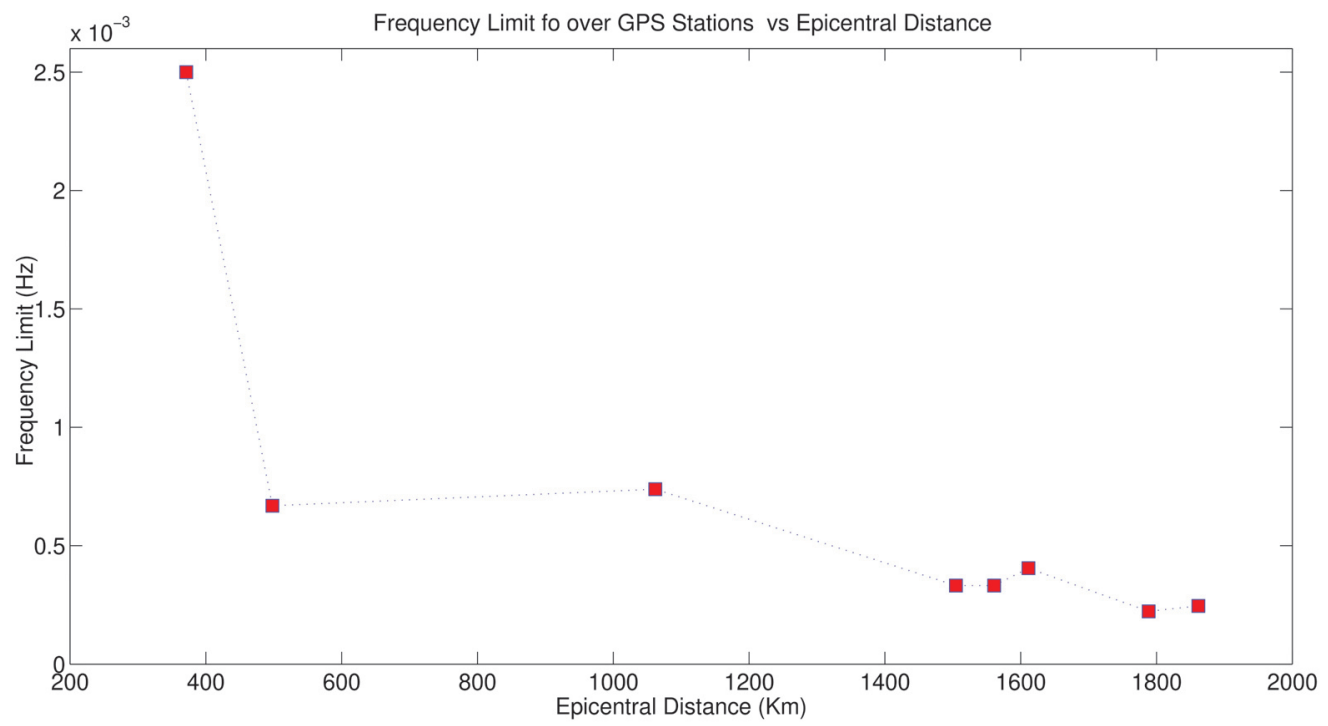

Figure 9. Variation of TEC turbulence frequency limit fo over the GPS Stations of EUREF, with the epicentral distance around the day of the earthquake of 17 November, 2015 occurrence.

From the same Figures we realize that the TEC turbulence frequency limit $f_{\mathrm{o}}$ over the ORID station is significantly higher than that over MATE station despite their relatively small difference of their distance from Lefkada. According to Hobara et al., [2005] there might be a lot of reasons for this discrepancy. Nevertheless the LAIC mechanism [Hayakawa et al., 2011; Hayakawa, 2011] offers a probable explanation: From the Figure 4 we realize that the Compliance parameter $p$ indicate that in the year 2015 the broader area of Ohrid is in critical tectonic stress state. 
Thus, we suggest that the micro seismic activity $(M<3.2)$ in November of this year may probably be responsible for the replenishment of the ionospheric turbulence content with high frequency constituents [Molchanov et al., 2004; 2006].

\section{Detection of VLF/LF disturbances.}

As a part of the International Network for Frontier Research on Earthquake Precursors (INFREP) [Biagi et al., 2011] a receiver in Thessaloniki, Greece $\left(40.59^{\circ} \mathrm{N}, 22.78^{\circ} \mathrm{E}\right)$ is monitoring VLF transmitters based in Tavolara, Italy, Niscemi, Italy, Keflavik, Iceland, and Anthorn, UK. The data is being processed by a method of normalization according to the distance between the receiver and the transmitter and then they are processed by the Hilbert Huang Transform (HHT) to produce the corresponding spectra for visual analysis [Skeberis et al., 2015].

Table 5 displays the characteristic of the transmitters used by the Network of INFREP, while Figure 10 shows the INFREP network and the transmission paths of transmitters to the receiver of Thessaloniki. The nearest to Lefkada transmission paths are shown with white arrows.

\begin{tabular}{|c|c|c|c|}
\hline Freq. (KHz) & Station & Location & Lat/Lon \\
\hline 19.58 & GBZ & Anthorn, UK & $54^{\circ} 54^{\prime} 40^{\prime \prime} \mathrm{N} 03^{\circ} 16^{\prime} 48^{\prime \prime} \mathrm{W}$ \\
\hline 20.27 & ICV & Tavolara, IT & $40^{\circ} 54^{\prime} 22^{\prime \prime} \mathrm{N} 09^{\circ} 42^{\prime} 48^{\prime \prime} \mathrm{E}$ \\
\hline 23.4 & HWU & Le Blanc, FR & $53^{\circ} 04^{\prime} 57^{\prime \prime} \mathrm{N} 07^{\circ} 36^{\prime} 55^{\prime \prime} \mathrm{E}$ \\
\hline 37.5 & ICE & Keflavik, ID & $64^{\circ} 01^{\prime} 00^{\prime \prime} \mathrm{N} 22^{\circ} 34^{\prime} 00^{\prime \prime} \mathrm{W}$ \\
\hline 45.9 & NSY & Niscemi, IT & $37^{\circ} 07^{\prime} 32^{\prime \prime} \mathrm{N} 14^{\circ} 26^{\prime} 11^{\prime \prime} \mathrm{E}$ \\
\hline 153 & ROM & Brasov, RO & $45^{\circ} 45^{\prime} 17^{\prime \prime} \mathrm{N} 25^{\circ} 36^{\prime} 24^{\prime \prime} \mathrm{E}$ \\
\hline 180 & TRT & Polalti, TR & $39^{\circ} 45^{\prime} 22^{\prime \prime} \mathrm{N} 43^{\circ} 25^{\prime} 05^{\prime \prime} \mathrm{E}$ \\
\hline 183 & EU1 & Felsberg, DE & $49^{\circ} 16^{\prime} 49^{\prime \prime} \mathrm{N} 06^{\circ} 40^{\prime} 41^{\prime \prime} \mathrm{E}$ \\
\hline 198 & CN1 & Berkaoui, DZ & $31^{\circ} 55^{\prime} 14^{\prime \prime} \mathrm{N} 05^{\circ} 04^{\prime} 03^{\prime \prime} \mathrm{E}$ \\
\hline 270 & CZE & Topolna, CZ & $49^{\circ} 07^{\prime} 25^{\prime \prime} \mathrm{N} \quad 1^{\circ} 30^{\prime} 52^{\prime \prime} \mathrm{E}$ \\
\hline
\end{tabular}

Table 5. The Characteristic of the transmitters which are used by the Network of INFREP.

The signals from the VLF stations are of greater importance, as these stations are mainly military, and thus present greater reliability and robustness, rather than the LF stations that are mainly civilian radio stations. The stations that are chosen to be presented are GBZ, ICV, ICE, NSY as the most robust signals. For the purpose of completeness of the presentation of our data, the CN1 station is also presented, nonetheless from empirical evidence it does not provide reliable data due to the frequency of its transmission, being very high in the LF band. Being in the same path as NSY for this earthquake event, the NSY should be considered as more significant.

From Figures 11 to 15 that enhanced signal variations are presented at the closest to the earthquake epicenter transmissions paths the last 10 and even more days before the main shock. The main points of interest as denoted in the figures, are clustering around -2 days from the earthquake, and seem to overlap, especially on the VLF stations, and are more focused in the higher frequency range of the spectra, focused from $0.006 \mathrm{~Hz}$ to $0.009 \mathrm{~Hz}$. In the LF range the diurnal effect is evident, and not suppressed effectively due to the normalization applied, but noteworthy is the high level of disturbances in the ICV station, which is atypical for normal periods of operations. On the NSY station the closest on the path, the highest peak is after the earthquake event, which can be attributed to the ongoing seismic activity.

Lastly, the frequency range of the variations are focused on the $0.001 \mathrm{~Hz}$ to $0.009 \mathrm{~Hz}$ (period $1.66 \mathrm{~min}$ to $16.66 \mathrm{~min}$ ), making these results consistent with the results from the direct observation of TEC variations. 
Dimitrios N. Arabelos et al.

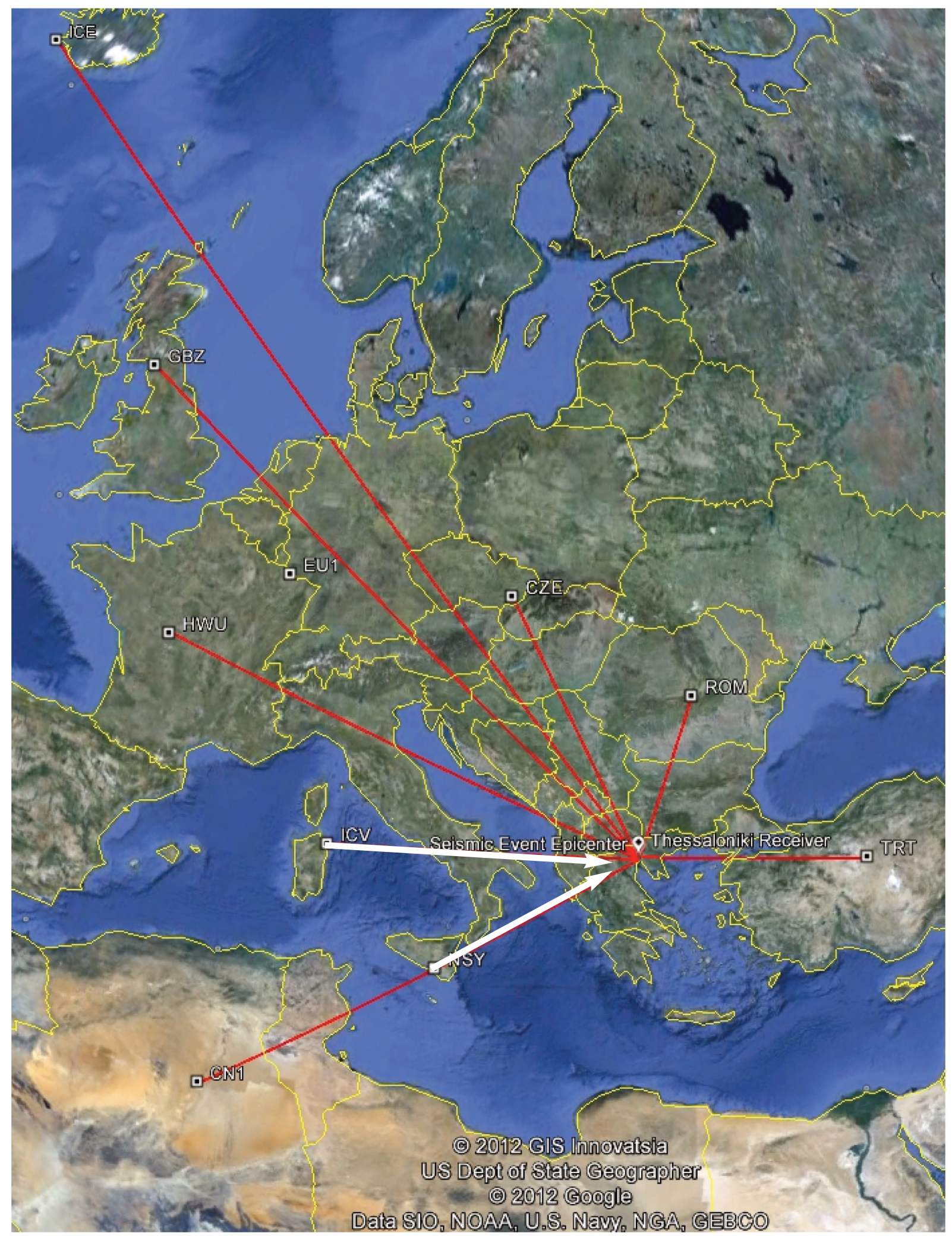

Figure 10. The INFREP network and the transmission paths of transmitters to the receiver of Thessaloniki. 


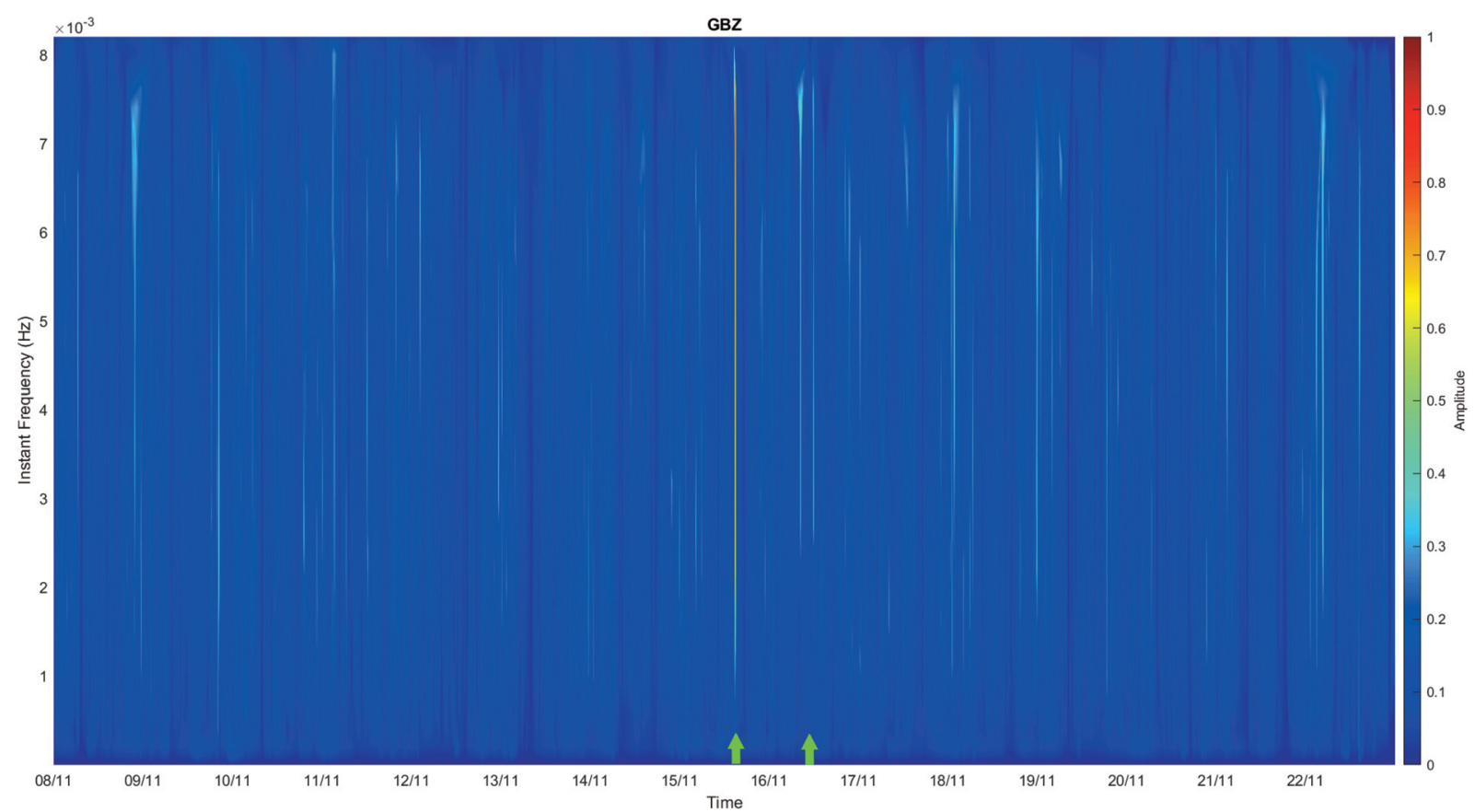

Figure 11. VLF disturbances of the transmission path GBZ-Thessaloniki. Green arrow denotes points of interest.

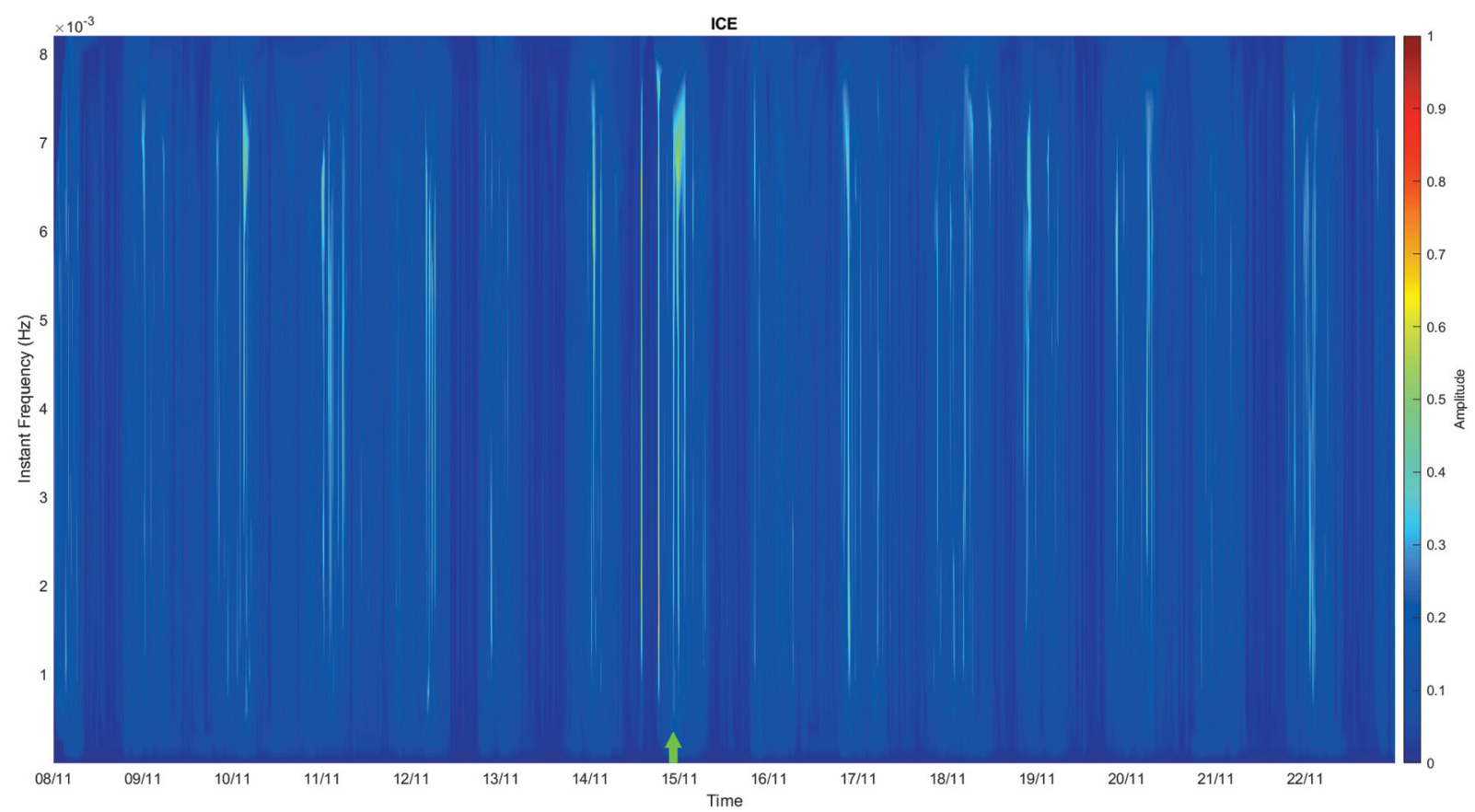

Figure 12. VLF disturbances of the transmission path ICE-Thessaloniki. Green arrow denotes points of interest. 
Dimitrios N. Arabelos et al.

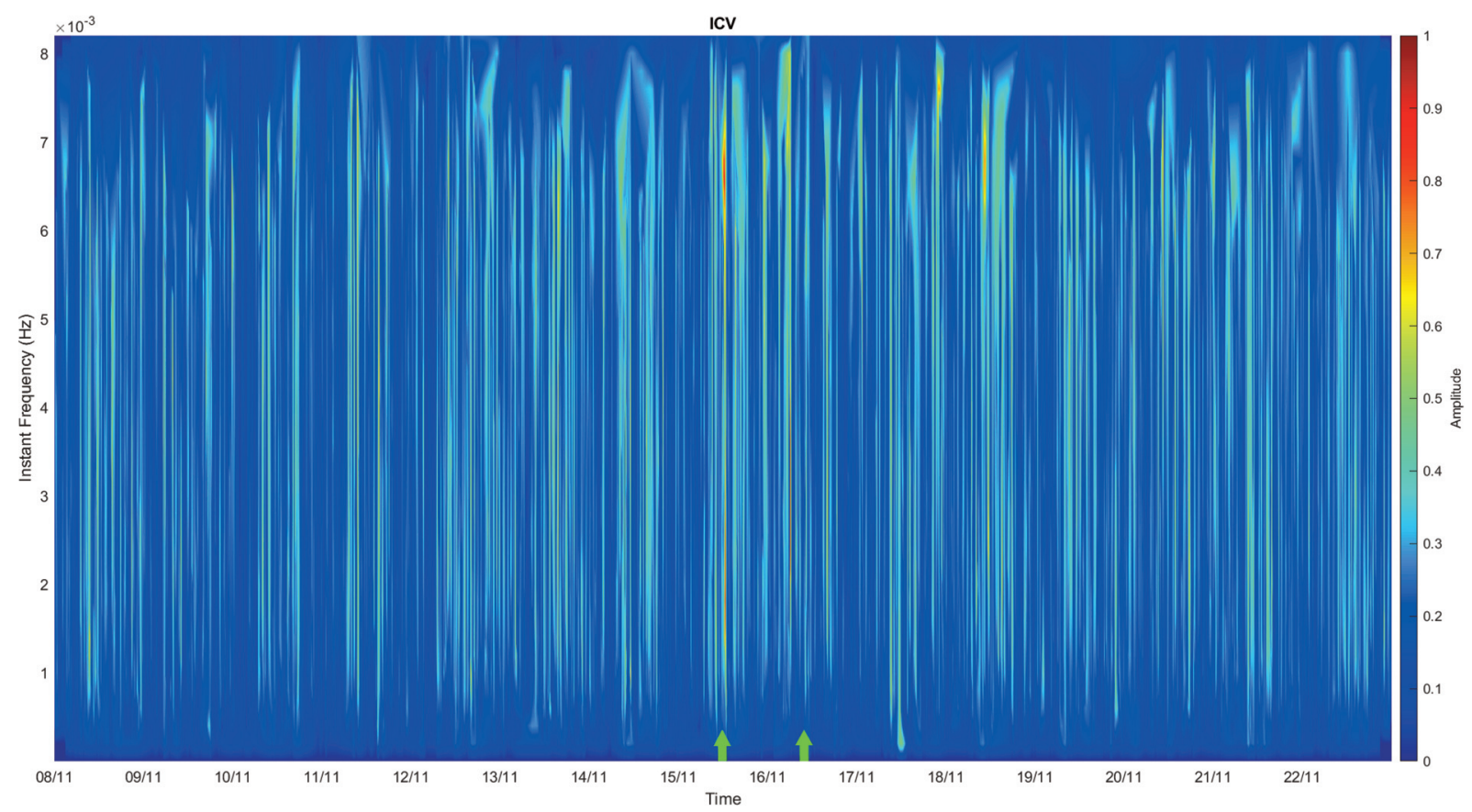

Figure 13. VLF disturbances of the transmission path ICV-Thessaloniki. Green arrow denotes points of interest.

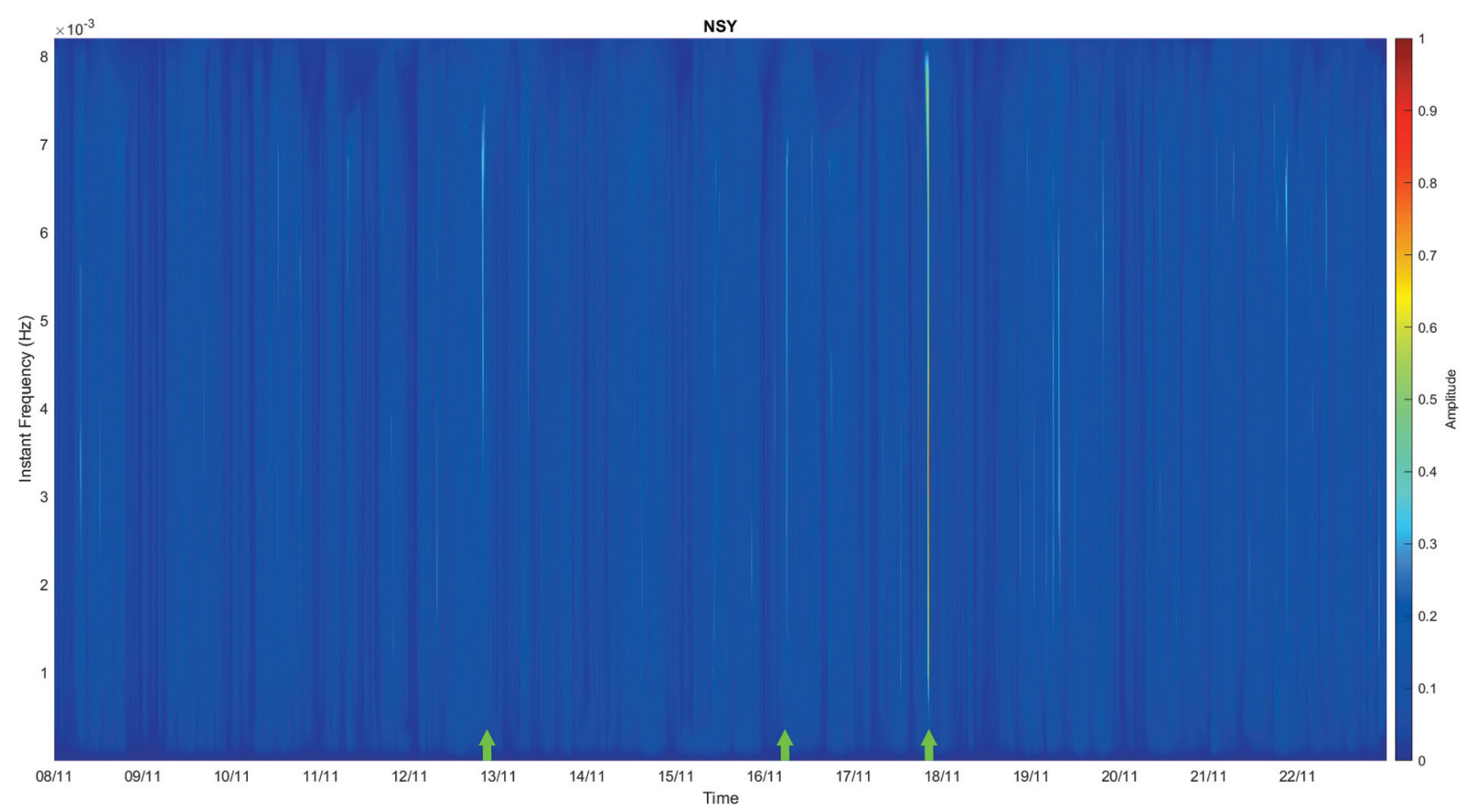

Figure 14. VLF disturbances of the transmission path NSY-Thessaloniki. Green arrow denotes points of interest. 


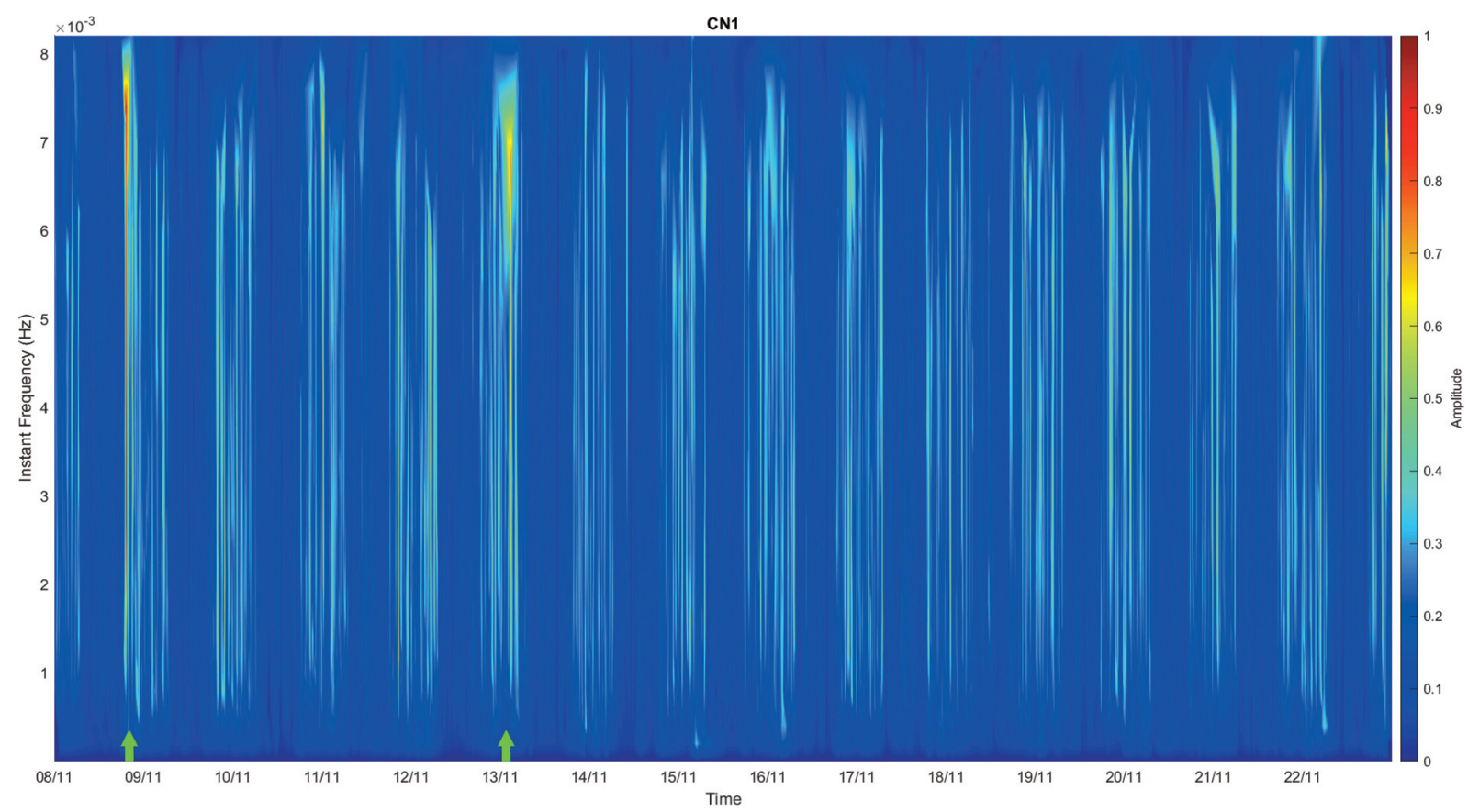

Figure 13. VLF disturbances of the transmission path CN1-Thessaloniki. Green arrow denotes points of interest.

\section{Concluding remarks}

In this research we show that the "Planetary seismic hazard indices" may be used, in combination with other tectonic information, i.e. tectonic history of the area, for a reliable forecasting of strong earthquakes. In addition they have the great advantage that the relative data are easily accessible as products of national or international multipurpose monitoring campaigns. In particular, in this work we have showed that the "Earth tides-seismicity compliance parameter" $p$ may be used as a medium time earthquake warning. In particular the mapping of $p$ values underlines the areas where the tectonic stresses have a critical level and drown the attention of the authorities for a pending earthquake. Of course, the magnitude depends on the tectonic characteristic and the history of the area. On the other hand the time and space variation of the ionospheric turbulence frequency content over the earthquake epicenter, deduced directly from GPS TEC observations or indirectly through the VLF transmission, may be used for the short time earthquake forecasting.

Acknowledgements. The authors are grateful to Professors F. Arikan and U. Sezer, the persons in charge of IONOLAB, for their willingness to provide any useful information about the data of IONOLAB.

\section{References}

Arabelos, D.N., E.M. Contadakis,, G.S. Vergos and S.D. Spatalas (2016). Variation of the Earth tide-seismicity compliance parameter during the recent seismic activity in Fthiotida, central Greece, Annals of Geophysics, 59, 1, S0102.

Arikan, F., A. Yilmaz, O. Arikan, I. Sa Yin, M. Gurun and S.A. Yildirim (2009). Space Weather Activities of IONOLAB Group: TEC Mapi, Geoph. Res. Abstr., 11.

Biagi, P.F., T. Maggipinto, F. Righetti, D. Loiacono, L. Schiavulli, T. Ligonzo, A. Ermini, I.A. Moldovan, A.S. Moldovan, A. Buyuksarac, H.G. Silva, M. Bezzeghoud and M.E. Contadakis (2011). The European VLF/LF radio network to 


\section{Dimitrios N. Arabelos et al.}

search for earthquake precursors: setting up and natural/man-made disturbances, Nat. Hazards Earth Syst. Sci., $11,333-341$.

Contadakis, M.E., D.N. Arabelos, G. Asteriadis, S.D. Spatalas and C. Pikridas (2008). TEC variations over the Mediterranean during the seismic activity period of the last quarter of 2005 in the area of Greece, Nat. Hazards and Earth Syst. Sci., 8, 1267-1276.

Contadakis, M.E., D. N. Arabelos and S. Spatalas (2009). Evidence for tidal triggering on the shallow earthquakes of the seismic area of Mygdonia basin, North Greece, in Terrestrial and Stellar Environment, eds. D. Arabelos, M.E. Contadakis, C. Kaltsikis, I.N. Tziavos, Ziti Press Thessaloniki, Greece, 223-235.

Contadakis, M.E., D.N. Arabelos and S. Spatalas (2012a). Evidence for tidal triggering for the earthquakes of the Ionian geological zone, Greece, Annals of Geophysics, 55, 1, 73-81.

Contadakis, M. E., D.N. Arabelos, G. Asteriadis, S.D. Spatalas and C. Pikridas (2012b). TEC variations over Southern Europe before and during the M6.3 Abruzzo earthquake of $6^{\text {th }}$ April 2009, Annals of Geophysics, 55, 1, 83-93.

Contadakis, M.E., D.N. Arabelos, G. Vergos, S. D. Spatalas, S.D. and M. Skordilis (2015). TEC variations over the Mediterranean before and during the strong earthquake $(M=6.5)$ of 12th October 2013 in Crete, Greece, Phys. Chem. Earth, 85, 9-16.

Hayakawa, M. (2011). On the fluctuation spectra of seismo-electromagnetic phenomena, Nat. Hazards Earth Syst. Sci., 11, 301-308.

Hayakawa, M., Y. Kasahara, T. Nakamura, Y. Hobara, A. Rozhnoi, M. Solovieva, O.A. Molchanov and V. Korepanov (2011). Atmospheric gravity waves as a possible candidate for seismo-ionispheric perturbations, J. Atmos. Electr., 32, 3, 129-140.

Hobara, Y., F. Lefeuvre, M. Parrot and O.A. Molchanov (2005). Low-latitude ionospheric turbulence observed by Aureol-3 satellite, Annales Geophysicae, 23, 1259-1270

Louvari, E., A.A. Kiratzi and B.C. Papazachos (1999). The Cephalonia Transform Fault and its extension to western Lefkada Island (Greece), Tectonophysics, 308, 223-236.

Molchanov, O., P.F. Biagi, M. Hayakawa, A. Lutikov, S. Yunga, D. Iudin, S. Andreevsky, A. Rozhnoi, V. Surkov, V. Chebrov, E. Gordeev, A. Schekotov and E. Fedorov (2004). Lithosphere-atmosphere-ionosphere coupling as governing mechanism for preseismic short-term events in atmosphere and ionosphere, Nat. Hazards Earth Syst. Sci., 4, 5/6, 757-767.

Molchanov, O., A. Schekotov, M. Solovieva, E. Fedorov, V. Gladyshev, E. Gordeev, V. Chebrov, D. Saltykov, V.I. Sinitsin, K. Hattori and M.Hayakawa (2005). Near seismic effects in ULF fields and seismo-acoustic emission: statistics and explanation, Nat. Hazards Earth Syst. Sci., 5, 1-10.

Papadopoulos G.A, V.K. Karastathis, A. Ganas, S. Pavlides, A. Fokaefs, and K. Orfanogiannaki (2003). The Lefkada, Ionian Sea (Greece), shock ( $M w$ 6.2) of 14 August 2003: Evidence for the characteristic earthquake from seismicity and ground failures, Earth Planets Space, 55, 713-718.

Rozhnoi A., M. Solovieva, M. Parrot, M.Hayakawa, P. F. Biagi and K. Schwingenschuh (2012). Ionospheric turbulence from ground-based and satellite VLF/LF transmitter signal observations for the Simushir earthquake (November 15, 2006), Annals of Geophysics, 55, 1, doi:10.4401/ag-5190

Schuster, A. (1897). On lunar and solar periodicities of earthquakes, Proc. R.Soc. Lond., 61, 455-465.

Scordilis, E.M., G.F. Karakaisis, B.G. Karakostas, D.G. Panagiotopoulos, P.E. Comninakis and B.C. Papazachos (1985). Evidence for transform faulting in the Ionian Sea: The Cephalonia Island earthquake sequence of 1983, Pure Appl. Geophys., 123, 3, 388-397, DOI:10.1007/BF00880738.

Skeberis, C., Z.D. Zaharis, T.D. Xenos, S. Spatalas, D.N. Arabelos and M.E. Contadakis (2015). Time-frequency analysis of VLF for seismic-ionospheric precursor detection: Evaluation of Zhao-Atlas-Marks and HilbertHuang Transforms. Phys. Chem. Earth, Parts A/B/C, 85, 174-184

Tanaka, S., M. Ohtake and H. Sato (2002), Evidence for tidal triggering of earthquakes as revealed from statistical analysis of global data. J. Geophys. Res., 107, (5B10), 2211.

Tanaka, S., H. Sato, S. Matsumura and M. Ohtake (2006), Tidal triggering of earthquakes in the subducting Philipine Sea plate beneath the locked zone of the plate interface in Tokai region, Japan. Tectonopysics, 417, 69-80.

Turcotte, D.L. (1997). Fractal and Chaos in Geology and Geophysics (2 ${ }^{\text {nd }}$ Edition), Cambridge University Press, Cambridge U. K.

Vergos, G., D.N. Arabelos and M.E. Contadakis (2015). Evidence for Tidal triggering on the earthquakes of the Hellenic Arc, Greece., Phys. Chem. Earth 85-86, 210-215. 
Valkaniotis S., A. Ganas, G. Papathanasiou and M. Papanikolaou (2014). Field observations of geological effects trigger by the January-February 2014 Cephalonia (Ionian Sea,Greece), Tectonophysics, 630, 150-157.

Corresponding author: Dimitrios N. Arabelos, Department of Geodesy and Surveying, Aristotle University of Thessaloniki, Thessaloniki, email: arab@eng.auth.gr

"CORRESPONDING AUTHOR: Dimitrios N. ARABELOS

Department of Geodesy and Surveying, Aristotle University of Thessaloniki, Greece email:arab@eng.auth.gr (c) 2020 the Istituto Nazionale di Geofisica e Vulcanologia. All rights reserved 